\title{
Scaled Conjugate Gradient Backpropagation Algorithm for Selection of Industrial Robots
}

\author{
Sasmita Nayak ${ }^{*}$, Dr. Neeraj Kumar ${ }^{+}$, Dr. B. B. Choudhury ${ }^{\#}$ \\ *Ph.D Research Scholar, Suresh Gyan Vihar University, Jaipur, Rajasthan, India. \\ ${ }^{+}$Department of Mechanical Engineering, Suresh Gyan Vihar University, Jaipur, India. \\ \# Department of Mechanical Engineering, IGIT, Sarang, Odisha, India.
}

\begin{abstract}
:
Purpose: Development of industrial robots and its usage by different manufacturing industries in lot many diverse applications is a very much serious task for the selection of robots. As a consequence, the selection process of the robot becomes incredibly complicated for the potential users because they have a large set of attributes and parameters of the robots are available at their disposal. Moreover, the proposed work gives the efficient decision for the selection of the robots to the potential users of the robots or robot manufacturer.
\end{abstract}

Design/methodology/approach: In this paper, it has been proposed that the scaled conjugate gradient fastest back-propagation algorithm used for the optimized way of selection of robot based on the appropriate parameters.

Findings: The ranks of the desired industrial robots are evaluated using the proposed algorithm from the entire best possible robot that specifies the most genuine yardstick of robot selection for the particular application. The complete design performance of the proposed method discussed with different prediction errors such as mean square error, root mean square error, and R-squared error.

Originality/value: The proposed methodology is an original scientific work and the algorithm used is an efficient algorithm for the selection of industrial robot. In this work, ten numbers of parameters of the robot are used for the selection of the industrial robot and eight broad categories of the robot are proposed called robot-rank.

Keywords: backpropagation, industrial robot, neural network, scaled conjugate gradient

\section{Introduction}

In modern engineering and technology robots is the primary tool in a variety of advanced manufacturing facilities. The numbers of robot manufacturers are also ever-increasing with many different ranges. The selection of the robot to suitable for a particular implication and the production environment from the enormous number of robots available in the market becomes a difficult task. Various considerations such as availability, production systems, and economics need to be considered. Moreover, many of the attributes are differ in nature and contain different units. However, none of these solutions may take care of all the demands and constraints of specific applications. Paul and Nof. compared humans to robots. Vukobratovic found that the spherical configuration was superior to other configurations. Khouja presented the application of data envelopment analysis (DEA) in the first phase and a multi-attribute decision-making method in the second phase. However, DEA requires more 
computation and if the number of factors that the decision maker willing to consider is vast and the number of alternative robots are smaller than DEA may be a poor discriminator. Here the Author's quote example of twenty-seven alternative robots with four attributes robot selection. Again, DEA may be at a disadvantage in terms of its rationale, suppose the decision maker is unfair with linear programming concepts. Liang and Wang proposed a robot selection algorithm, which was used to find out decision makers fuzzy evaluations about robot selection factor weightings. The Chu and Lin pointed out the limitations of Liang and Wang method and proposed a fuzzy-TOPSIS technique for robot selection. However, the authors had converted the available objective values for the robot selection factors into fuzzy values that, violate the fundamental rule of fuzzy logic. Further, only a 5-point scale was adopted for the rating of robots under subjective factors. Also, the fuzzy method is complicated and needs more processing power. Agrawal et al. presented a multiple attribute decision making (MADM) approach 'TOPSIS' for selection of a robot for industrial application i.e. considering four attributes and five alternatives robots. Rao et al. have proposed a digraph and matrix methods for robot selection. Agrawal et al. have identified four attributes for the given industrial application and five robots have been shortlisted. In this paper, the attributes considered are same as of Agrawal et al., and degree of freedom is beneficial attributes, and higher quantitative values are desirable. However, for qualitative attributes lower values are desirable and obtained from the robot selection attributes digraph. This method is uncomfortable if the decision maker is unfamiliar with graph theory and matrix method concepts. Babatunji Omoniwa presented a Multi-Criteria Robot Selection Problems (MCRSPs) using Grey Relational Analysis (GRA). Moreover, concluded that the distinguishing coefficient has a minimal impact on GRA, this approach makes more appropriate for accurate selection of robot. Chatterjee et.al. solved two real-time robot selection problems using visekriterijumsko kompromisno rangiranje (VIKOR) method and Elimination and Choice Expressing Reality (ELECTRE) methods. Parkan and Wu made particular emphasis on a performance measurement procedure termed operational competitiveness rating (OCRA) and multiple-attribute decision-making method, TOPSIS. The final selection was prepared by averaging the results of OCRA, TOPSIS, and a utility model. Suprakash Mondal, S. Chakraborty, presented, four models of data envelopment analysis (DEA), specified additive, and cone-ratio models with respect to cost and process optimization. Also, multi-attribute decision-making concept has been employed in arriving at the best robot selection. The objective of a robot selection process is to identify the robot selection factors and obtain the most appropriate combination. Efforts need to be extended using a logical approach, to eliminate unsuitable robots, and selection of a proper robot. In this paper, we have proposed the robot selection using the Scaled Conjugate Gradient Backpropagation Algorithm.

\section{Manipulator Attributes of the Industrial Robot}

The manipulators play the significant role to specify the potentiality of the robot in a broad range of applications. In most case, the user needs to be backed in classifying the attributes of the robot logically by avoiding the confusion in various techniques. If this can make a proper way, then the selection of the robot for particular applications could be precise. A robot manipulator can specify by some quantitative attributes such as payload capacity, 
DOI: https://dx.doi.org/10.26808/rs.ca.i7v6.12 International Journal of Computer Application (2250-1797)

Volume 7- No.6, November-December 2017

horizontal reach, repeatability, and so on. However, some attributes such as built quality, after sales service, and so on, that cannot be expressed quantitatively. There are some attributes, which can be found out by mathematical model and analysis. For instance, reliability can be expressed in terms of Mean Time between Failure (MTBF) or Mean Time to Repair (MTTR) methods. While experimentation shall determine some attributes like life expectancy if not provided by the manufacturer. The various pertinent attributes help the user to create a database. The manipulators attribute types found out based on general parameters, physical parameters, and performance, and so on, as given the in Table 1. The case of operation, termed as manipulability, can be quantified as manipulability measure, and is used as an attribute. The primary manipulator attributes used for selection of the robot efficiently.

\begin{tabular}{|l|l|}
\hline \multicolumn{1}{|c|}{ Attributes type } & \multicolumn{1}{|c|}{ Parameter } \\
\hline General & Price ranges, robot type and coordinate system \\
\hline Physical & $\begin{array}{l}\text { Actuator type, robot weight, robot size, } \\
\text { grippers type, number of axes, space } \\
\text { requirements of the robot }\end{array}$ \\
\hline Performance & $\begin{array}{l}\text { Payload of robot, workspace, stroke, } \\
\text { maximum end effector speed, accuracy, } \\
\text { repeatability, resolution }\end{array}$ \\
\hline Structure/ Architecture & Degree of freedom, type of joints \\
\hline Applications & Working environment \\
\hline Sophistication & Maintainability and Safety Features \\
\hline Control/ feedback system & $\begin{array}{l}\text { Control robotic joints, gripper control, sensors, } \\
\text { programming method, number of input and } \\
\text { output channels of controller }\end{array}$ \\
\hline Availability/ Reliability & Downtime and Reliability \\
\hline
\end{tabular}

Table 1. Major manipulator attributes

\section{Proposed Methodology for the Selection of Industrial Robot}

In this section, we have discussed two things. In the first part, we have discussed the proposed method scaled conjugate gradient based back-propagation algorithm used for selection of industrial robots. In the second part proposed the workflow for the selection of the rank of the industrial robot using the proposed method scaled conjugate gradient based back-propagation algorithm.

\subsection{Proposed Scaled Conjugate Gradient Based Back-propagation Algorithm for Robot Selection}

Industrial robot selection models are complex nonlinear systems that can be solved using robust estimation methodologies like neural network algorithms. In this work, neural network pattern classification technique is proposed for the prediction of manipulator attributes, i.e. quantitative attributes as well as qualitative attributes. A feedforward neural network is trained using different training functions that update weight and bias values. In this work training algorithm such as scaled conjugate gradient are studied for the implementation of robots selection prediction techniques. 
DOI: https://dx.doi.org/10.26808/rs.ca.i7v6.12 International Journal of Computer Application (2250-1797)

Volume 7- No.6, November-December 2017

Scaled conjugate gradient (SCG) is a supervised learning algorithm used for feedforward neural networks $(\mathrm{NN})$ and the member of the class of conjugate gradient methods. SCG uses similar concepts of the general optimization strategy, but chooses the search direction and step size more effectively by using information from the second order approximation is represented by equation 1 .

$$
E(w+y) \approx E(w)+E^{\prime}(w)^{T}+\frac{1}{2} y^{T} E^{\prime \prime}(w) y
$$

In SCG, each iteration computes optimal distance. The line search is then performed to determine the optimal distance to move along the current search direction as equation 2 .

$w_{k+1}=w_{k}+a_{k} * p_{k}$

Then the next search direction is performed so that, the conjugated to previous search instructions. Actually $p_{k}$ is a function of $a_{k}$, the Hessian matrix of the error function and also the matrix of the second derivatives. SCG uses a scalar $\mathrm{a}_{\mathrm{k}}$ that is supposed to regulate the indefiniteness of the Hessian matrix.

\subsection{Proposed Workflow for the Selection of the Industrial Robot}

In general, a realistic robot must have minimum specifications that are equal to or better than equals to the minimal requirements for the desired application. For example, a material handling robot is not feasible unless its specification on payload equals or exceeds the weight of the heaviest part of it. The minimum requirement for this application is tabulated as shown in Table 2. Notice that a robot with specifications all equal to or better than the minimal prerequisites of the application that may nevertheless fail to present the required performance during operation. This failure is because, as discussed in the beginning, the manufacturer's specifications may not hold simultaneously. Table 2 summarizes the principal parameter requirements with its values for the selection of an industrial robot.

\begin{tabular}{|l|l|l|}
\hline Sl. No. & \multicolumn{1}{|c|}{ Parameter } & \multicolumn{1}{|c|}{ Values } \\
\hline 1 & Working envelope & Minimum $500 \mathrm{~mm}$ \\
\hline 2 & Payload & Minimum $5 \mathrm{KG}$ \\
\hline 3 & Repeatability & $\pm 0.1 \mathrm{~mm}$ \\
\hline 4 & $\begin{array}{l}\text { Work lot size } \\
\text { (Production rate per hour) }\end{array}$ & $\geq 25$ Tasks \\
\hline 5 & Maximum tip speed & Minimum $255 \mathrm{~mm} / \mathrm{sec}$ \\
\hline 6 & Degrees of freedom & 1 to 7 \\
\hline 7 & Controller type & 1 to 4 \\
\hline 8 & Actuator type & 1 to 3 \\
\hline 9 & Arm Geometry & $\leq 8$ \\
\hline 10 & Programming & $\leq 5$ \\
\hline
\end{tabular}

Table 2. Principal parameters required of a robot 
DOI: https://dx.doi.org/10.26808/rs.ca.i7v6.12 International Journal of Computer Application (2250-1797)

Volume 7- No.6, November-December 2017

We have proposed a ranking of the robots with respect to the primary parameters of the robot specified in Table 3.

\begin{tabular}{|l|l|l|l|l|l|l|l|l|l|l|}
\hline $\begin{array}{l}\text { Sl } \\
\text { no }\end{array}$ & \multicolumn{1}{|c|}{$\begin{array}{c}\text { Name of } \\
\text { Robot } \\
\text { Parameter }\end{array}$} & Unit & $\begin{array}{c}\text { Ran } \\
\mathbf{K} \\
\mathbf{1}\end{array}$ & $\begin{array}{c}\text { Rank } \\
\mathbf{2}\end{array}$ & $\begin{array}{c}\text { Rank } \\
\mathbf{3}\end{array}$ & $\begin{array}{c}\text { Rank } \\
\mathbf{4}\end{array}$ & $\begin{array}{c}\text { Rank } \\
\mathbf{5}\end{array}$ & $\begin{array}{c}\text { Rank } \\
\mathbf{6}\end{array}$ & $\begin{array}{c}\text { Rank } \\
\mathbf{7}\end{array}$ & $\begin{array}{c}\text { Rank } \\
\mathbf{8}\end{array}$ \\
\hline 1 & Repeatability & $\pm \mathrm{mm}$ & 5.5 & 5 & 4.5 & 4 & 3.5 & 2.5 & 1.5 & 1 \\
\hline 2 & $\begin{array}{l}\text { Work envelop } \\
\text { (reach })\end{array}$ & $\mathrm{Mm}$ & 500 & 1000 & 1500 & 2000 & 2100 & 2300 & 2500 & 2600 \\
\hline 3 & Payload & $\mathrm{Kg}$ & 10 & 20 & 30 & 40 & 50 & 70 & 90 & 100 \\
\hline 4 & Velocity & $\mathrm{mm} / \mathrm{s}$ & 500 & 1000 & 1500 & 2000 & 2500 & 3500 & 4500 & 5000 \\
\hline 5 & $\begin{array}{l}\text { Degrees of } \\
\text { freedom }\end{array}$ & Nos. & 1 & 2 & 3 & 4 & 5 & 7 & 7 & 7 \\
\hline 6 & $\begin{array}{l}\text { Production } \\
\text { rate }\end{array}$ & $\begin{array}{l}\text { Task/ } \\
\text { hour }\end{array}$ & 100 & 200 & 250 & 300 & 350 & 450 & 550 & 600 \\
\hline 7 & $\begin{array}{l}\text { Arm } \\
\text { Geometry }\end{array}$ & Nos. & 1 & 2 & 3 & 4 & 5 & 6 & 7 & 8 \\
\hline 8 & $\begin{array}{l}\text { Controller } \\
\text { type }\end{array}$ & Nos. & 1 & 1 & 1 & 2 & 2 & 3 & 4 & 4 \\
\hline 9 & $\begin{array}{l}\text { Actuator } \\
\text { Types }\end{array}$ & Nos. & 1 & 1 & 2 & 2 & 2 & 3 & 3 & 3 \\
\hline 10 & Programming & Nos. & 1 & 1 & 2 & 2 & 3 & 4 & 5 & 5 \\
\hline
\end{tabular}

Table 3. Proposed robot ranking chart

We have described the complete activities for selecting the rank of the robot in the proposed workflow diagram in figure 1.

\begin{tabular}{|l|}
\hline $\begin{array}{c}\text { Robot Specifications } \\
\text { as Inputs }\end{array}$ \\
\hline Repeatability \\
Work Envelope \\
Payload \\
Velocity \\
Degree of Freedom \\
Programming \\
Production Rate \\
Controller Type \\
Arm Geometry \\
Actuator Type \\
\hline
\end{tabular}

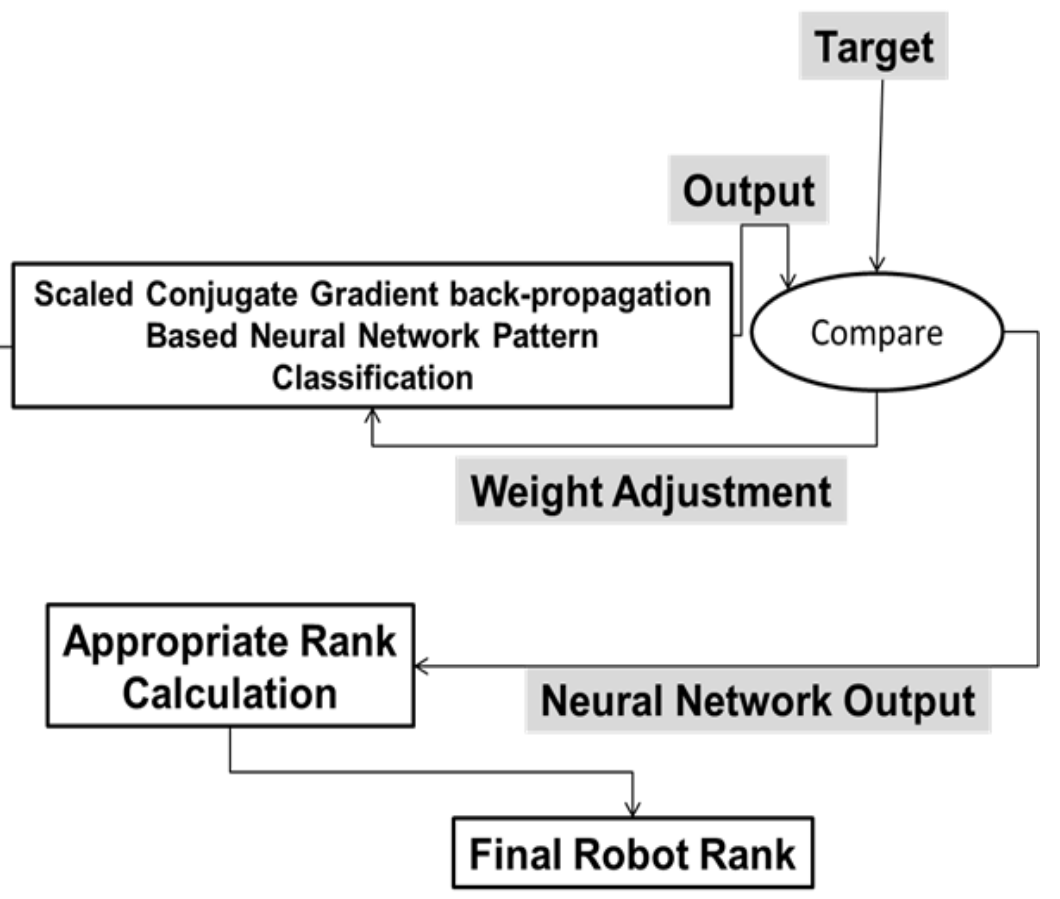

Figure 1. Proposed workflow diagram for selection of the robot rank 


\section{Results and Discussions}

The overall performance of the optimization techniques for the prediction of selection of industrial robots is examined by considering eleven manipulator attributes. The inputs attributes and output entity are listed in Table 4. MSE (Mean Square Error), RMSE (Root Mean Square Error), and R-squared error of the prediction are calculated and listed.

\begin{tabular}{|l|l|}
\hline \multicolumn{1}{|c|}{ Inputs } & \multicolumn{1}{c|}{ Output } \\
\hline Working Envelope (WE) & Ranking and selection of industrial robot (R) \\
Payload (PL) & \\
Repeatability (RE) & \\
Production rate (PR) & \\
Maximum tip speed (MTS) & \\
Degree of freedom (DOF) & \\
Controller type (CT) & \\
Actuator type (AT) & \\
Arm Geometry (AG) & \\
Programming (P) & \\
\hline
\end{tabular}

Table 4. Inputs and outputs used for prediction of the rank of the robot

Scaled conjugate gradient-based neural network pattern classification was used to predict the selection of robot from different industrial data. The prediction error with the target value and predicted value are plotted here. It has been observed from figure 2 that the actual result is matched correctly with the predicted values. Only rank 1, 2, 9, and 10 are having the minimum error, but others have almost $0 \%$ error. The ranking prediction response and error curve is shown in Figure 2.

\section{Load Prediction}
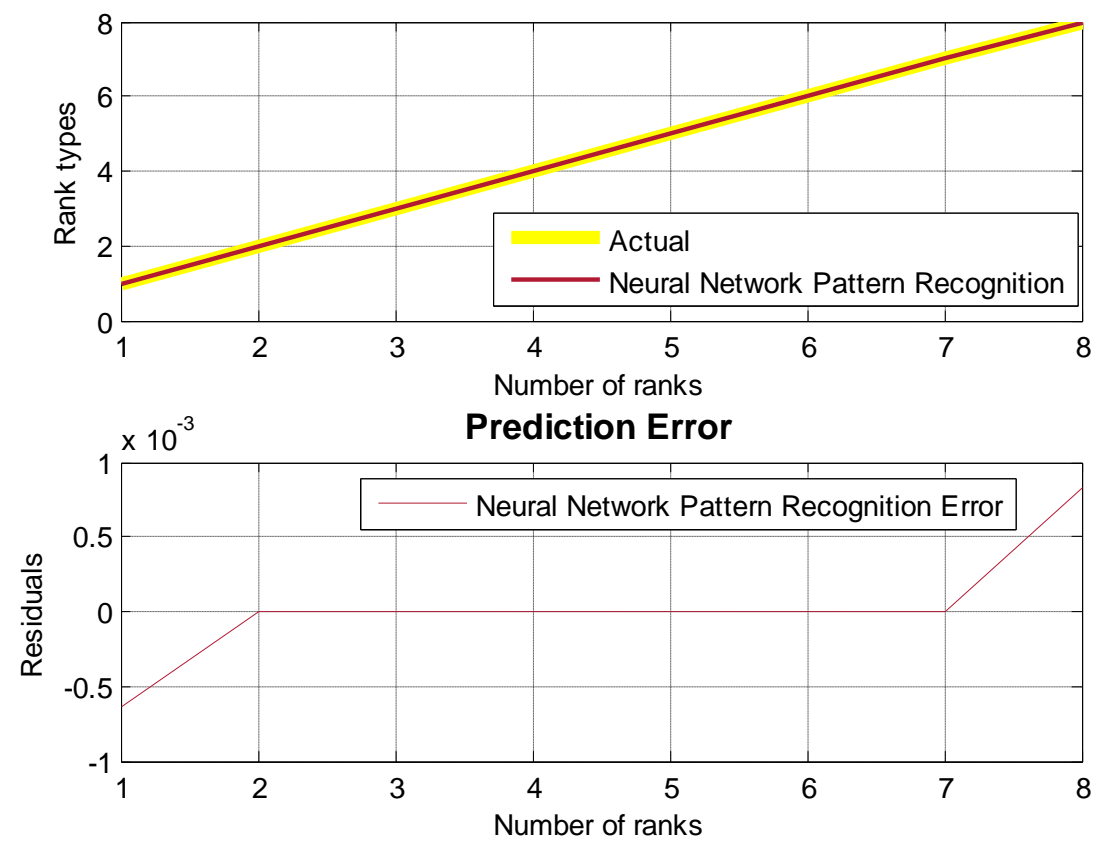

Figure 2. Actual rank type and predicted rank type v/s number of robot ranks.

The error graph plotted between residuals and number of rank [Scaled conjugate gradientbased neural network pattern classification]. The scaled conjugate gradient based BP neural 
DOI: https://dx.doi.org/10.26808/rs.ca.i7v6.12 International Journal of Computer Application (2250-1797)

Volume 7- No.6, November-December 2017

network pattern classification training performance is best achieved as shown in figure 3 . The best training performance is obtained using the proposed method at 511 epochs.

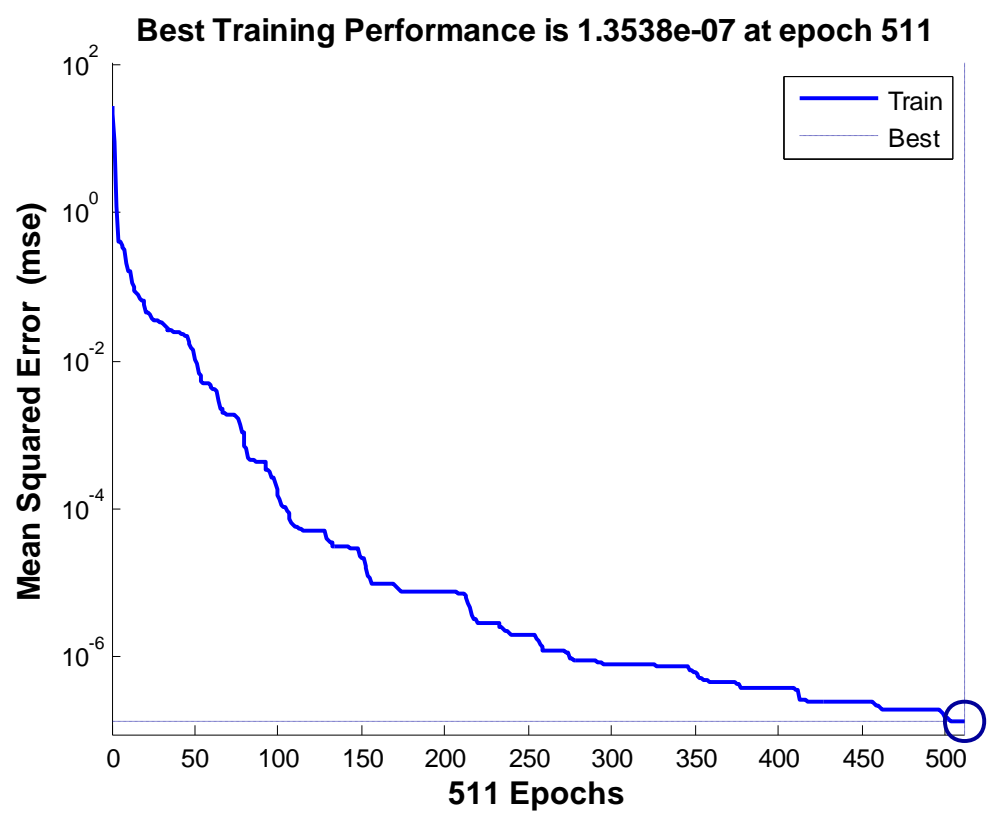

Figure 3. Scaled conjugate gradient based BP neural network pattern classification training performance.

Training state after neural network training based on the scaled conjugate gradient technique is shown in below figure 4 . The best training performance is obtained at 511 epochs.
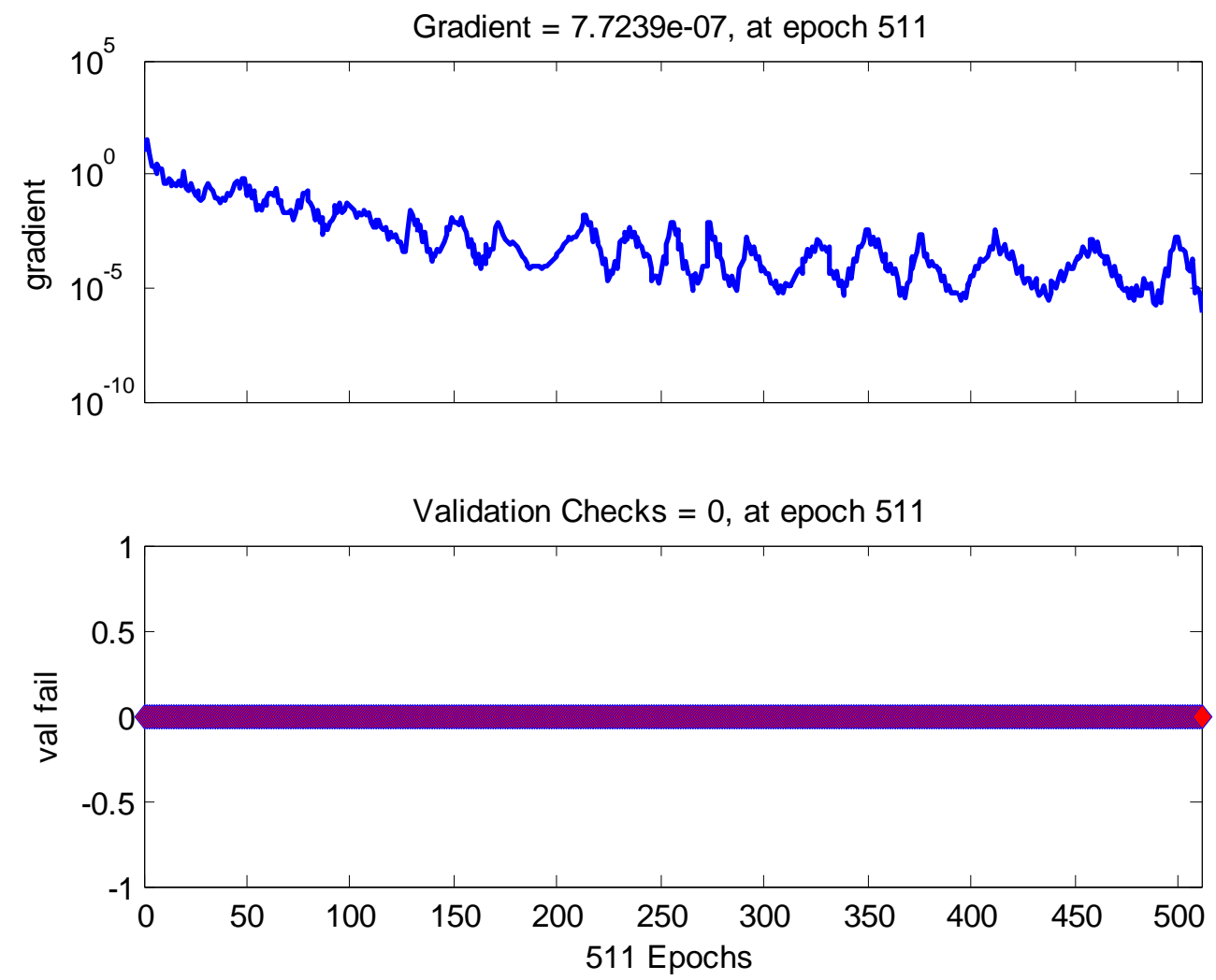

Figure 4. Training state after neural network training [Scaled conjugate gradient-based neural network pattern classification] 
DOI: https://dx.doi.org/10.26808/rs.ca.i7v6.12

International Journal of Computer Application (2250-1797)

Volume 7- No.6, November-December 2017

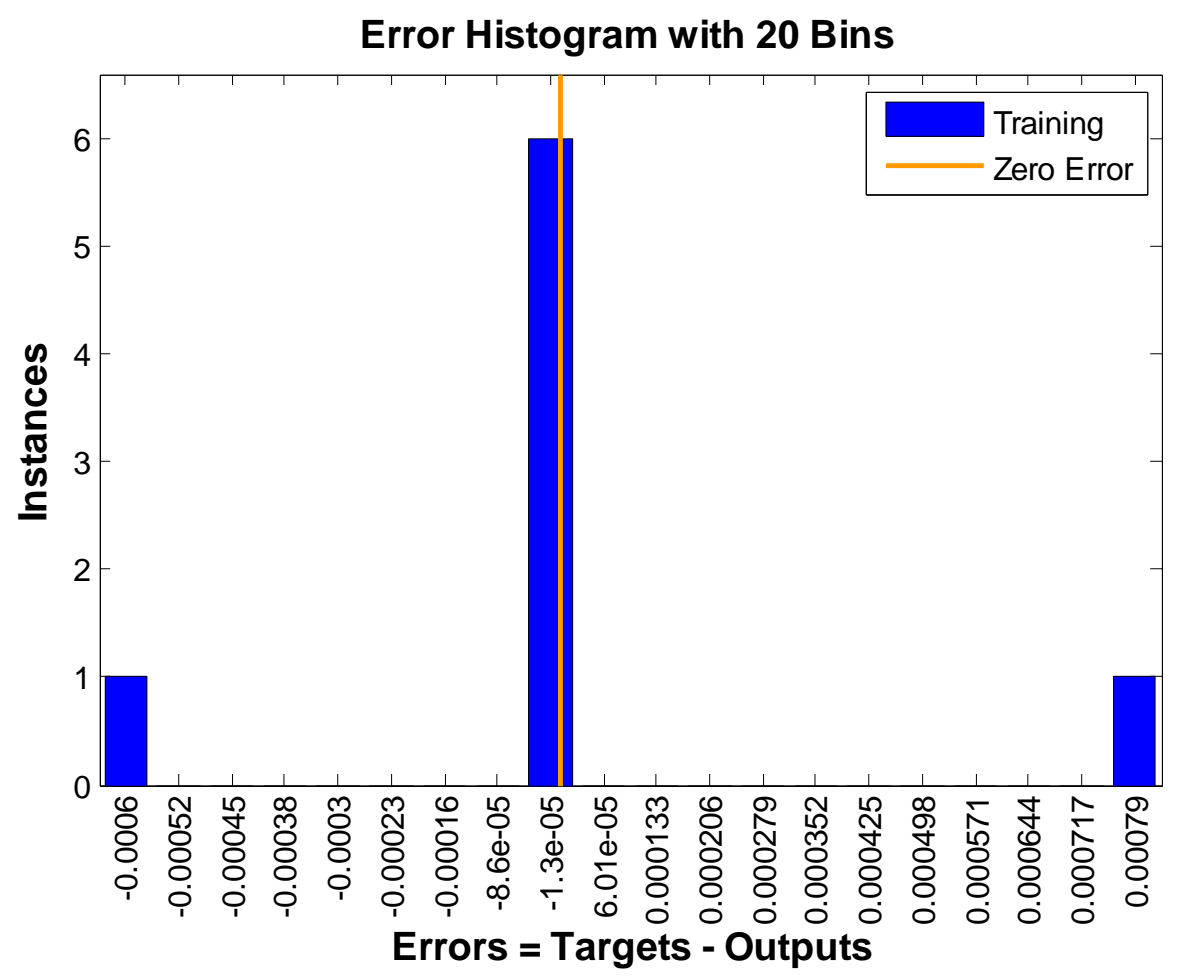

Figure 5. Error Histogram after training [Scaled conjugate gradient-based neural network pattern classification]
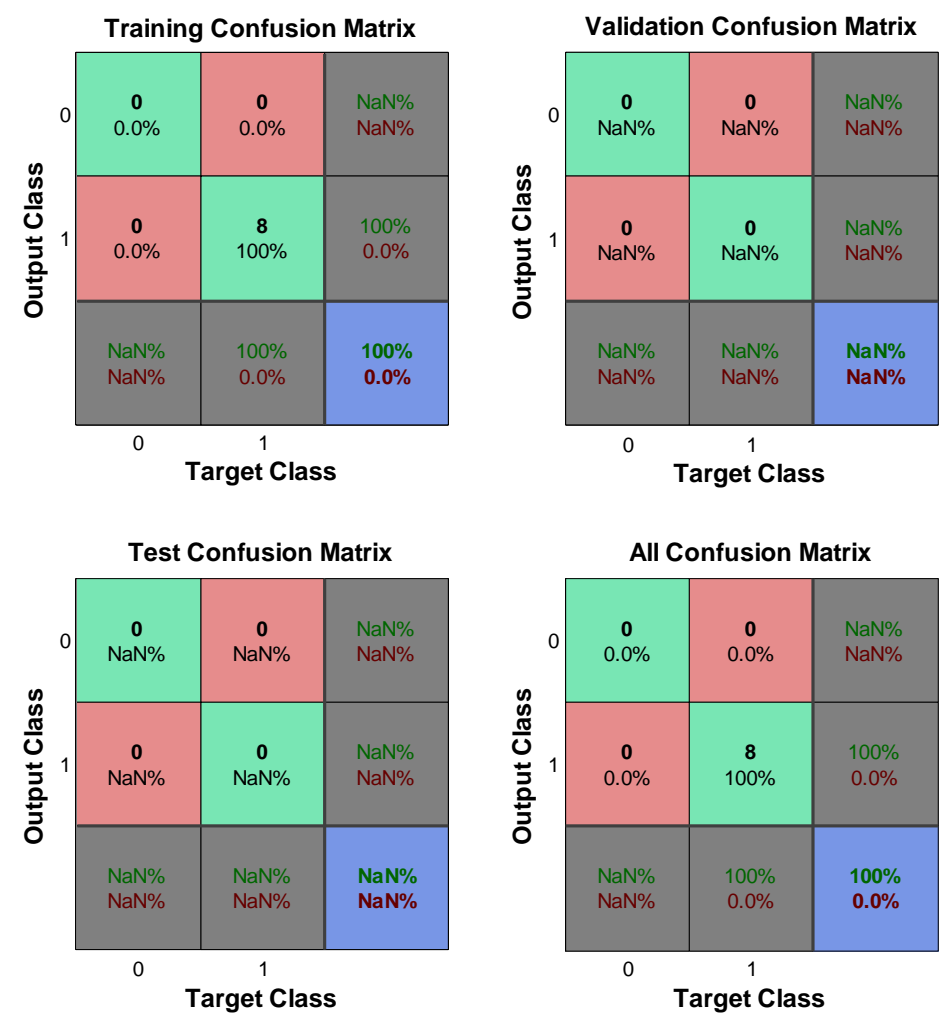

Figure 6. The confusion matrix of scaled conjugate gradient-based neural network pattern classification training. 
Error histogram after training performance by scaling the conjugate gradient-based neural network pattern classification is shown in below figure 5. "Instances v/s. Error Histogram" is plotted with 20 Bins. The confusion matrix of scaled conjugate gradient-based neural network pattern classification is shown in figure 6 . The errors obtained from the simulations are $\mathrm{RMSE}=3.6794 \mathrm{e}-04, \mathrm{MSE}=1.3538 \mathrm{e}-07, \mathrm{R}$-squared error $=1.0000$. It is observed that very efficient performance correctly predicts twenty-four data sets. The test inputs and outputs of the proposed method are listed in Table 5.

\begin{tabular}{|c|c|c|}
\hline Test Inputs & $\begin{array}{c}\text { Desired } \\
\text { Robot Rank(R) }\end{array}$ & $\begin{array}{l}\text { Neural Network Pattern } \\
\text { Classification Output }\end{array}$ \\
\hline $\begin{array}{l}\text { Repeatability }( \pm \mathrm{mm})=4 \\
\text { Work envelope }(\mathrm{mm})=2000 \\
\text { Payload }(\mathrm{Kg})=40 \\
\text { Velocity }(\mathrm{mm} / \mathrm{s})=2000 \\
\text { Freedom }=4 \\
\text { Production rate }(\text { Task/hour })=300 \\
\text { Controller }=2 \\
\text { Actuator }=2 \\
\text { Arm Geometry = Cylindrical light } \\
\text { Programming = Task-oriented } \\
\text { Programming }\end{array}$ & 4 & $\begin{array}{l}\text { Neural Network Training } \\
\text { Type: Scaled conjugate } \\
\text { gradient } \\
\text { Neural network classified } \\
\text { rank: } 4 \\
\text { Final Robot Rank : } 4\end{array}$ \\
\hline
\end{tabular}

Table 5. Test inputs and results of the proposed method

From our observation, the results obtained by our proposed method are very much consistent and produces qualitative results in comparison with the published methods. In the published papers, the methodology uses the least number of parameters compared with the proposed method. In addition to the above facts, the proposed method also offers a more objective, easy to use, and simple robot selection approach with maximum numbers of the major parameters of the robot.

\section{Conclusions}

The ranking of the industrial robot is efficiently predicted by taking various industrial robot parameters. It is observed that in the proposed method, we have taken ten input parameters for computation which is the better than the existing techniques. The performance analysis of the proposed optimization technique scaling the conjugate gradient-based neural network pattern classification is done by calculating MSE, RMSE, and R-squared error. The MSE and RMSE and R-squared error obtained by using the proposed neural network method are $1.3538 \mathrm{e}-07,3.6794 \mathrm{e}-04$ and 1.0000 . Hence, the above proposed method produces much better result as well as very mínimum error. Finally, it is recommended to all the clients of industrial robots to make use of the proposed method for an efficient way of selecting the industrial robot.

\section{References}

- Paul, R.P. and Nof, S. (1979). Work methods measurements-a comparison between robot and human task performance, International Journal of Production Research, 17, 277-303. 
- Agrawal, V.P., Kohli, V., Gupta, S. (1991). Computer aided robot selection: the multiple attribute decision-making approach, International Journal of Production Research, 29(8), 1629-1644.

- Andrei Neculai (2007). Scaled conjugate gradient(SCG) algorithms for unconstrained optimization, Computational Optimization and Applications, Springer-Verlag, 38(3), 401-416.

- Cetişli Bayram, Barkana Atalay (2010). Speeding up the scaled conjugate gradient (SCG) algorithm and its application in neuro-fuzzy classifier training, Soft Computing, SpringerVerlag, 4(4), 365-378.

- Liang, G.H., Wang, M.J. (1993). A fuzzy multicriteria decision-making approach for robot selection, Robotics and Computer Aided Manufacturing, 10, 267-274.

- Vukobratovic, M. (1982). Scientific fundamentals of industrial robots 1: Dynamics of manipulator robots theory, and applications, Springer-Verlag Publication, New York.

- Khouja, M. (1995). The use of data envelopment analysis for technology selection, Comput Ind Eng., 28, 123-132.

- Chu, T.C., Lin, Y.C. (2003). A fuzzy TOPSIS method for robot selection, International Journal of Advanced Manufacturing Technology, 21, 284-90.

- Parkan, C., Wu, M.L. (1999). Decision making and performance measurement models with applications to robot selection, Comput Ind Eng., 36, 503-523.

- Rao, R.V., Padmanabhan, K.K. (2006). Selection, identification and comparison of industrial robots using digraph and matrix methods, Robotics and Computer Integrated Manufacturing, 22, 373-383.

- Mondal, S., Chakraborty, S. (2013). A solution to robot-selection problems using data envelopment analysis, International Journal of Industrial Engineering Computations, 4, 355-372.

- Omoniwa, B. (2014). A solution to Multicriteria Robot Selection problems using Grey Relational Analysis," International Journal of Computer and Information Technology, $3(2)$.

- Athawale, V.M., Chatterjee, P., Chakraborty, S.(2010). Selection of industrial robots using compromise ranking method, International Conference on industrial engineering and operations management, 1-5. 